\title{
Estimación de la concentración de clorofila y su relación con la concentración de proteína cruda en tres especies del pasto Urochloa en el Piedemonte Llanero, Colombia
}

Estimating chlorophyll concentration and its relationship with crude protein concentration in three species of Urochloa in the Piedemonte Llanero, Colombia

\author{
ÁLVARO RINCÓN CASTILLO ${ }^{1}$, MAURICIO ÁLVAREZ DE LEÓN ${ }^{2}$, OSCAR PARDO BARBOSA ${ }^{1}$, MARY \\ ALEJANDRA AMAYA $^{1}$ Y RAÚL ALEJANDRO DÍAZ GIRALDO ${ }^{1}$ \\ ${ }^{1}$ Red de Ganadería y Especies Menores, Corporación Colombiana de Investigación Agropecuaria (Agrosavia), \\ C.I. La Libertad, Villavicencio, Meta, Colombia. www.agrosavia.co \\ ${ }^{2}$ Red de Cultivos Transitorios, Agrosavia, C.I. La Libertad, Villavicencio, Meta, Colombia. www.agrosavia.co
}

\section{Resumen}

Para conocer la relación entre la intensidad del color verde de las hojas y la concentración de proteína cruda (PC) foliar en los pastos Urochloa brizantha, $U$. decumbens y $U$. humidicola en el Piedemonte Llanero de Colombia, se midió la concentración de la clorofila en las hojas (en unidades SPAD), se relacionó con la intensidad del color verde según la Tabla Munsell y se comparó con la concentración de PC determinada por el método Kjeldahl. El análisis de regresión entre las concentraciones de clorofila y PC mostró coeficientes de determinación $\left(\mathrm{r}^{2}\right)$ entre 0.76 y 0.88 . Aunque los datos obtenidos no permiten generar para las tres especies estudiadas tablas colorimétricas concluyentes basadas en la Tabla Munsell, las relaciones obtenidas son de utilidad para asistir a los productores en sus decisiones sobre la utilización y la fertilización de pasturas de la región.

Palabras clave: Clorofilómetro, índice de verdor, nitrógeno, SPAD, Tabla Munsell.

\section{Summary}

To establish the relationship between the intensity of the green color of leaves and their crude protein $(\mathrm{CP})$ concentration in Urochloa brizantha, $U$. decumbens and $U$. humidicola pastures in the Piedemonte Llanero, Colombia, the leaf chlorophyll concentration was measured (in SPAD units), classified based on the Munsell color chart and compared with the leaf $\mathrm{CP}$ concentration determined by the Kjeldahl method. The regression analysis between chlorophyll and $\mathrm{CP}$ concentrations showed coefficients of determination $\left(\mathrm{r}^{2}\right)$ between 0.76 and 0.88 . While collection of additional data will allow colorimetric charts based on the Munsell color chart to be developed which can be used to predict CP levels for each of these species, the relationships generated can be used to develop recommendations to assist farmers in the region in their decisions on use and fertilizing of these pastures.

Keywords: Chlorophyll meter, leaf greenness, Munsell color chart, nitrogen, SPAD.

\section{Introducción}

En gramíneas tropicales el conocimiento de la concentración de nitrógeno $(\mathrm{N})$ es fundamental para la toma de decisiones en relación con el uso del forraje y la necesidad de fertilización (Pardo y Pérez 2010). Como una alternativa a la determinación de la concentración de $\mathrm{N}$ por métodos analíticos convencionales, como el

Correspondencia: Álvaro Rincón C., Agrosavia, C.I. La Libertad, km 17 vía a Puerto López, Meta, Colombia.

Correo electrónico: arincon@ agrosavia.co 
método Kjeldahl, se ha propuesto la medición de la concentración de clorofila en las hojas y la correlación de la intensidad del color verde con la concentración de proteína cruda (PC) foliar. Esta metodología ha sido exitosamente probada no solo en cultivos como algodón (Neves et al. 2005) y maíz (Argenta et al. 2001; Zotarelli et al. 2003) sino también en algunos pastos, p.ej. Cynodon dactylon cv. Tifton 85 (Silva et al. 2009) y Urochloa brizantha cv. Marandu (Guimarães et al. 2011).

Esta metodología se basa en que el $\mathrm{N}$ es esencial para la formación de la clorofila y hace parte del anillo tetrapirrol que conforma esta molécula (Salisbury y Ross 1994). La concentración de la clorofila se determina con instrumentos como el clorofilómetro y se expresa en grados SPAD (Soil Plant Analysis Development) (Spectrum Technologies 2009). Además, para su determinación se pueden usar equipos con sensores remotos proximales y de contacto que se apoyan en las propiedades reflectivas de las plantas en diferentes regiones del espectro electromagnético (Morais et al. 2011; Zuffo et al. 2012). La intensidad del color verde es cuantificada por comparación utilizando la Tabla Munsell. Esta tabla de colores para tejido de plantas se divide en cinco clases principales: verde, rojo, amarillo, azul y púrpura y presenta subdivisiones como verdeamarillo y amarillo-rojo indicando por un lado, el grado de tono claro u oscuro y por otro el grado de saturación o matiz del color (Munsell Color 1977).

Debido a la alta acidez y baja fertilidad de los Oxisoles que predominan en los Llanos Orientales de Colombia, la producción de biomasa de los pastos cultivados es baja y la calidad nutritiva es afectada principalmente en términos de la concentración de PC (Rincón 2012). Una metodología que permita una rápida evaluación de la concentración de PC foliar en los pastos sería una herramienta útil para la toma de decisiones por parte de los ganaderos respecto al momento apropiado para el ingreso de los animales a las pasturas y para la aplicación de fertilizantes. En este contexto se realizó este estudio, con el objetivo de relacionar las concentraciones de clorofila y PC, y el color de las hojas, en especies de Urochloa ampliamente cultivadas en la región de los Llanos Orientales de Colombia.

\section{Materiales y Métodos}

El estudio se desarrolló durante la época de lluvias (abrilnoviembre) en la Orinoquia colombiana, en la subregión del Piedemonte Llanero que hace parte de la cordillera oriental de los Andes en Colombia, en un Oxisol de la terraza media del Centro de Investigación La Libertad de la Corporación Colombiana de Investigación Agropecuaria (Agrosavia), ubicado en el municipio de Villavicencio, Meta, a $9^{\circ} 06^{\prime} \mathrm{N}$ y $73^{\circ} 4^{\prime} \mathrm{O}$, a 330 m.s.n.m. Los pastos estudiados fueron Urochloa decumbens (sin. Brachiaria decumbens) cv. Decumbens, U. humidicola (sin. B. humidicola; antes: B. dictyoneura) cv. Llanero y $U$. brizantha (sin. B. brizantha) cv. Toledo.

Las muestras para los análisis fueron tomadas en pasturas manejadas con pastoreo rotacional y una edad de rebrote entre 25 y 35 días. El muestreo fue dirigido: de cada pasto se eligieron entre 350 y 400 hojas con diferentes tonalidades de color verde. En el tercio medio de cada hoja se determinó la concentración de clorofila (en grados SPAD) con un clorofilómetro portátil (Minolta Chlorophyll Meter SPAD-502 ${ }^{\circledR}$ ) para formar grupos de rangos de concentración de clorofila. La intensidad del color verde de 50 hojas en cada grupo fue comparada con los valores de referencia en la Tabla de colores Munsell. Las hojas en cada grupo fueron secadas a $60{ }^{\circ} \mathrm{C}$ durante 24 horas en estufa para determinar posteriormente la concentración de proteína cruda $(\% \mathrm{~N} \times 6.25)$ por el método Kjeldahl en el Laboratorio de Nutrición Animal de Agrosavia. Para calcular las ecuaciones de regresión entre las concentraciones de clorofila (valores SPAD) y las de PC se usó el programa estadístico SAS 9.3.

\section{Resultados}

Los datos obtenidos para cada especie se agruparon en 7 rangos de grados SPAD, con variaciones de 5 unidades para cada rango (Cuadro 1).

Cuadro 1. Rangos de concentración de clorofila en especies de Urochloa agrupados por grados SPAD.

\begin{tabular}{cc}
\hline Grupo & Concentración de clorofila (grados SPAD) \\
\hline 1 & $\leq 20$ \\
2 & $21-25$ \\
3 & $26-30$ \\
4 & $31-35$ \\
5 & $36-40$ \\
6 & $41-45$ \\
7 & $46-50$ \\
\hline
\end{tabular}

En los Cuadros 2, 3 y 4 se presentan para cada una de las 3 gramíneas estudiadas las concentraciones de clorofila (en grados SPAD) y de PC, y el color de las respectivas hojas. Se observó un incremento de la concentración de PC y de la intensidad del color verde a medida que incrementó la concentración de clorofila. 
Cuadro 2. Concentración de proteína cruda y color de las hojas en 7 grupos de concentración de clorofila en hojas de Urochloa decumbens cv. Decumbens. Llanos Orientales de Colombia.

\begin{tabular}{cccl}
\hline $\begin{array}{c}\text { Rango de concentración de clorofila } \\
\text { (grados SPAD) }\end{array}$ & $\begin{array}{c}\text { Proténa cruda } \\
(\%)\end{array}$ & $\begin{array}{c}\text { Rango de códigos en } \\
\text { Tabla Munsell }\end{array}$ & Rango de colores según Tabla Munsell \\
\hline$\leq 20$ & 7.2 & 5 GY $6 / 8-7 / 10$ & \\
$20-25$ & 8.1 & 5 GY 5/8 - 5/10 & \\
$26-30$ & 9.5 & 5 GY $4 / 8-5 / 8$ & \\
$31-35$ & 10.7 & 5 GY 4/8 - 5/6 & \\
$36-40$ & 12.6 & 5 GY 4/6 - 4/8 & \\
$41-45$ & 15.9 & 5 GY 4/4 - 4/6 & \\
$46-50$ & 17.7 & 5 GY 4/4 - 4/6 & \\
\hline
\end{tabular}

Cuadro 3. Concentración de proteína cruda y color de las hojas en 7 grupos de concentración de clorofila en hojas de Urochloa brizantha cv. Toledo. Llanos Orientales de Colombia.

\begin{tabular}{cccc}
\hline $\begin{array}{c}\text { Rango de concentración de clorofila } \\
\text { (grados SPAD) }\end{array}$ & $\begin{array}{c}\text { Proteína cruda } \\
(\%)\end{array}$ & $\begin{array}{c}\text { Rango de códigos en } \\
\text { Tabla Munsell }\end{array}$ & Rango de colores según tabla Munsell \\
\hline$\leq 20$ & 4.5 & 5 GY 6/8 - 7/8 & \\
$20-25$ & 5.3 & 5 GY 5/8 - 6/8 \\
$26-30$ & 7.4 & 5 GY 5/8 - 5/6 \\
$31-35$ & 7.7 & 5 GY 5/6 - 4/8 & \\
$36-40$ & 8.8 & 5 GY 4/6 - 4/8 & \\
$41-45$ & 9.6 & 5 GY 4/4 - 4/6 & \\
$46-50$ & 12.0 & 5 GY 4/6 - 4/4 & \\
\hline
\end{tabular}

Cuadro 4: Concentración de proteína cruda y color de las hojas en 7 grupos de concentración de clorofila en hojas de Urochloa humidicola cv. Llanero. Llanos Orientales de Colombia.

\begin{tabular}{cccc}
\hline $\begin{array}{c}\text { Rango de concentración de clorofila } \\
\text { (grados SPAD) }\end{array}$ & $\begin{array}{c}\text { Proteína cruda } \\
(\%)\end{array}$ & $\begin{array}{c}\text { Rango de códigos en } \\
\text { Tabla Munsell }\end{array}$ & Rango de colores según tabla Munsell \\
\hline$\leq 20$ & 4.5 & 5 GY 6/8 - 7/8 & \\
$20-25$ & 4.7 & 5 GY 5/8 - 6/8 \\
$26-30$ & 5.7 & 5 GY 5/6 - 5/8 \\
$31-35$ & 6.6 & 5 GY 5/6 - 4/8 & \\
$36-40$ & 7.5 & 5 GY 4/6 - 4/8 & \\
$41-45$ & 9.2 & 5 GY 4/6 - 4/4 & \\
$46-50$ & 12.5 & 5 GY 4/4 - 4/6 & \\
\hline
\end{tabular}


En el Cuadro 5 se presenta la relación entre la concentración de clorofila y la de PC en las hojas de las gramíneas estudiadas, con coeficientes de determinación $\left(r^{2}\right)$ que variaron entre 0.76 y 0.88 .

Cuadro 5. Ecuaciones de regresión entre las concentraciones de clorofila (grados SPAD) y proteína cruda para los pastos Urochloa decumbens $\mathrm{cv}$. Decumbens, $U$. brizantha cv. Toledo y $U$. humidicola cv. Llanero. Llanos Orientales de Colombia.

\begin{tabular}{lcc}
\hline Pasto & Ecuación & $\mathrm{r}^{2}$ \\
\hline cv. Decumbens & $\mathrm{Y}=0.12+0.3646 \mathrm{x}$ & 0.88 \\
\hline cv. Toledo & $\mathrm{Y}=0.73+0.2289 \mathrm{x}$ & 0.76 \\
\hline cv. Llanero & $\mathrm{Y}=0.504+0.202 \mathrm{x}$ & 0.84 \\
\hline
\end{tabular}

\section{Discusión}

Los resultados mostraron una relación alta $\left(\mathrm{r}^{2}=>0.76\right)$ entre la concentración de clorofila y la de PC foliar de las especies estudiadas. Los coeficientes de determinación son similares a los encontrados por Silva et al. (2009) para la relación entre $\mathrm{N}$ foliar $\left(\mathrm{g} / \mathrm{m}^{2}\right)$ y grados SPAD en el pasto Tifton $85\left(r^{2}=0.74\right)$ y por Guimarães et al. (2011) para la relación entre PC y grados SPAD en el pasto $U$. brizantha cv. Marandu $\left(\mathrm{r}^{2}=0.96\right)$.

Los resultados mostraron, además, que en un mismo rango de grados SPAD se presentaron diferencias entre los cultivares con respecto a la concentración de PC, mientras que los códigos de colores de la Tabla Munsell fueron similares. Por ejemplo, el valor más alto de PC correspondió al código 5GY 4/4-4/6 de la Tabla Munsell con 17\% de PC para el cv. Decumbens, mientras que este mismo valor Munsell correspondió a 10.5 y 12\% de PC para los cvs. Toledo y Llanero, respectivamente. Es posible que estas diferencias sean debidas a diferencias genéticas ya que el cv. Decumbens es un pasto adaptado al bajo suministro de $\mathrm{N}$ (Rao et al. 1998) y en condiciones de baja fertilidad presenta mayor concentración de PC (Pardo 1998).

Cuando se relacionó la concentración de clorofila con la de PC y los colores en la Tabla Munsell en un mismo cultivar, se presentó repetición en los códigos, encontrándose cercanía y traslape entre los tonos de verde de los grupos establecidos. Esto podría ser debido a la sensibilidad del ojo humano y la consiguiente subjetividad influenciada por la iluminación del ambiente. De todas maneras, no fue posible establecer para un mismo cultivar una relación entre la concentración de PC y los códigos de la Tabla de colores Munsell. Para una acertada asignación del valor de color Munsell o de algún otro patrón de color, habría que introducir en la metodología la conformación de páneles de análisis sensoriales de color.

\section{Conclusión}

Fue posible establecer relación entre la concentración de $\mathrm{N}$ (proteína cruda) y la de clorofila (medida en grados SPAD) para los cultivares estudiados. Por tanto el uso de un clorofilómetro portátil tiene el potencial de asisitir a los ganaderos en la toma de decisiones sobre prácticas de pastoreo y fertilización en el Piedemonte de los Llanos Orientales de Colombia.

\section{Referencias}

(Nota de los editores: todos los enlaces se verificaron el 31 de octubre de 2019.)

Argenta G; Silva PRF da; Bortolini CG; Forsthofer EL; Strieder ML. 2001. Relação da leitura do clorofilômetro com os teores de clorofila extraível e de nitrogênio na folha de milho. Revista Brasileira de Fisiologia Vegetal 13:158-167. doi: $10.1590 / \mathrm{S} 0103-31312001000200005$

Guimarães MMC; Matsumoto SN; Figueiredo MP; Cruz PG; Araújo GS. 2011. Estimativa da composição química do capim Braquiária cv. Marandú por meio de um clorofilômetro portátil. Revista Brasileira de Tecnologia Aplicada nas Ciências Agrárias 4(2):85-91. bit.ly/2Nsw3r3

Morais RR de; Teixeira PC; Lima WAA de; Rocha RNC da; Castellani DC; Silva AC da. 2011. Relação da leitura do clorofilômetro com os teores de macro e micronutrientes em folíolos de dendezeiro em sistema agroflorestal. Anais do VIII Congresso Brasileiro de Sistemas Agroflorestais, Belém, PA, Brasil. bit.ly/33iXkTs

Munsell Color. 1977. Munsell color charts for plant tissues. Munsell Color, Baltimore, MD, USA.

Neves OSC; Carvalho JG de; Martins FAD; Pádua TRP de; Pinho PJ de. 2005. Uso do SPAD 502 na avaliação dos teores foliares de clorofila, nitrogênio, enxofre, ferro e manganês do algodoneiro herbáceo. Pesquisa Agropecuária Brasileira 40(5):71-87. doi: 10.1590/S0100-204X200500 0500014

Pardo O. 1998. Gramíneas y leguminosas adaptadas a las condiciones de los Llanos Orientales. En: Pardo O; Rincón A; Hess D, eds. Alternativas forrajeras para los Llanos Orientales de Colombia. Boletín técnico 18. Corporación Colombiana de Investigación Agropecuaria - Corpoica. Villavicencio, Meta, Colombia. p. 9-22. hdl.handle.net/ 20.500.12324/18512

Pardo O; Pérez O. 2010. Alternativas forrajeras para los Llanos Orientales de Colombia. En: Rincón A; Jaramillo CA, eds. Establecimiento, manejo y utilización de recursos forrajeros en sistemas ganaderos de suelos ácidos. Corporación Colombiana de Investigación Agropecuaria - Corpoica, Villavicencio, Meta, Colombia. p. 27-73. hdl.handle.net/20. $\underline{500.12324 / 12703}$

Rao IM; Kerridge PC; Macedo MCM. 1998. Requerimientos nutricionales y adaptación a los suelos ácidos de especies de Brachiaria. En: Miles JW; Maass BL; Valle CB do, eds. Brachiaria: Biology, agronomy, and improvement. Centro 
Internacional de Agricultura Tropical (CIAT); Empresa Brasilera de Pesquisa Agropecuária (Embrapa), Cali, Colombia. p. 58-78. hdl.handle.net/10568/55295

Rincón A. 2012. Concentración de minerales en suelos y fertilización de pastos en los Llanos Orientales de Colombia. En: Rincón A; Jaramillo CA, eds. Manejo de la nutrición mineral en sistemas ganaderos de los Llanos Orientales de Colombia. Corporación Colombiana de Investigación Agropecuaria - Corpoica, Villavicencio, Colombia. p. 113164. hdl.handle.net/20.500.12324/12469

Salisbury FB; Ross CW. 1994. Fisiología vegetal. 4a Edn. Grupo Editorial Iberoamérica, México D.F.

Silva RVMM; Rossiello ROP; Barbieri Júnior É; Morenz MJF. 2009. Relação entre o acúmulo foliar de nitrogênio e leituras de um clorofilômetro, no capim Tifton 85. Anais do XIII
Encontro Latino Americano de Iniciação Científica e IX Encontro Latino Americano de Pós-Graduação, São José dos Campos, SP, Brasil, 16-17 octubre 2009. bit.ly/2WI8oaB

Spectrum Technologies. 2009. SPAD 502 Plus Chlorophyll Meter instruction manual. Spectrum Technologies, Plainfield, IL, USA. bit.ly/34nq65H

Zotarelli L; Cardoso EG; Piccinin JL; Urquiaga S; Boddey RM; Torres E; Alves BJR. 2003. Calibração do medidor de clorofila Minolta SPAD-502 para avaliação do conteúdo de nitrogênio do milho. Pesquisa Agropecuária Brasileira 38:1117-1122. doi: 10.1590/S0100-204X2003000900014

Zuffo AM; Andrade FR; Schossler TR; Milhomem DM; Piauilino AC. 2012. Eficiência na determinação indireta do nitrogênio foliar a partir do índice SPAD. Enciclopédia Biosfera 8:802-820. bit.ly/36sqRMv

(Recibido para publicación 14 mayo 2019; aceptado 23 agosto 2019; publicado 30 noviembre 2019)

(C) 2019

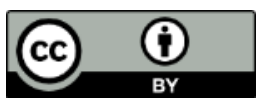

Tropical Grasslands-Forrajes Tropicales es una revista científica de acceso abierto publicada por el Centro Internacional de Agricultura Tropical (CIAT), en asocio con la Chinese Academy of Tropical Agricultural Sciences (CATAS). Este trabajo se publica bajo la licencia Creative Commons Atribución 4.0 Internacional (CC BY 4.0). 